\title{
中國科學院所長會議物理學 數學組會議總結
}

物理學、數學粗的所長會議, 根據國家的要求 和我們的主觀力量, 認真地討諭了各研究所幾年 內的工作力向和重點以及如何開展研究工作的閣 題。會議是在下述的基礎上召開的：（1）根㹉國 家邀波時期的總路綫、第一個五年計劃的基本任 䂇及文敉工作的總方針，科學院的工作有了百明 確的方问。（2）通過訪蘇代表團的工作，學留了

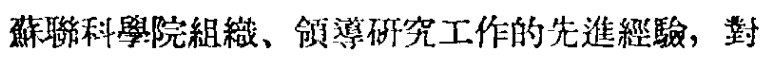
於蘇聨科學發屡的道路及內容有了初步的了解, 給我們在討論自己的工作時, 提供了很好的寥考 估掉。（3）1953 年是我們按照計劃進行工作的第 一年，各單位已認真地執行了三個季度的工作計 劃, 初步估計, 1953 年的研究計劃可完成 $80 \%$, 取得了一定的成績, 闹時也取得了一定的經驗和 敦訓。

在這次會議中, 各研究所報告了工作, 介紹 了情况, 使䂯究所與研究所之間能進一步地相互 了解, 第令後配合聯系的改善打下基礎。討論中 也㡎掦了批評與自我批評的精神，對院的領導提 出了意見，這煋於改進我們的工作是有很大好處 的。會中鞋各研究所的工作，屡開了討論，提出 了許多建設性的意見, 從而確定了各研究所的方 向。

\section{$=$

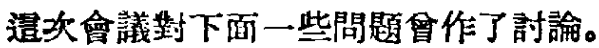

（1）機構的調整問題: 篇了集中力量，加强 領導, 搞好工作, 將電子學研究所籌備處與物理 研究所合併，作雼物理學的一個部門隶發展。數 學研究所的電子計算機組, 也併入物理研究所的 霍子學組, 㑨幾年後作出一定成精時, 业交回數
學研究所, 成立計算空, 篇全院及其他方面腿: 務。這樣否得多㨢㩲子，分散力量。

（2）各研究單位的工作方針問題：會議中明 確了物理學、數學科學四個㸴究單位——數祭研 究所、紫金川天文台、物理䂙究所、應用物理研 究所一一都是基礎科學的研究所。它們研究的科 學是許多其他科學的基礎，因此，應該促進其他 科學的發屡，篇技術科學開湖湴路，而技術科學 和其他科學的發展也能促使物理學、數學，科學 不斷前進。基礎科學的研究工作，不能與國家的

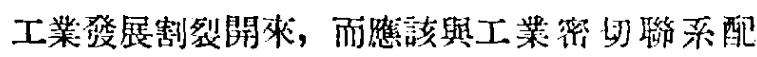
合, 否則就會建立在不可靠的基礎与。

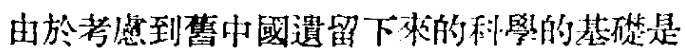

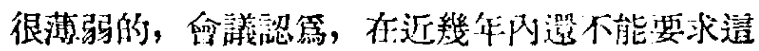

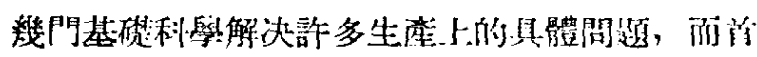
先應該注意的是基本的重要的闵键性的間題。我

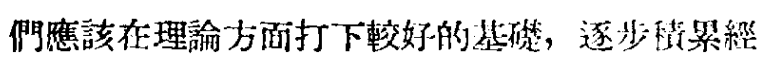
驗, 使物理學、數學、天文學在我㽣生根; 隻備 在一定時期後能够有力量范立地解决產業部門所 提出的重大科學理論問題。

這絕不是說目前就可以完全扡開生產叮的望 際問題不管。對於翰部的技術剖梾有谷的工作以 及訂了合同的工作和絕院批准的工作，邆是應荄 淮行的; 關於大的帶有根本性的問題的科學研究, 更必須要作。此外, 有些技術問題, 如檢鰞工作

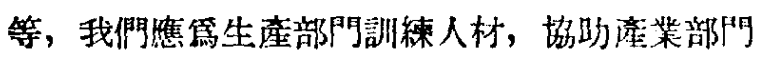
把研究、检驗機構建立起來。问時也否該考應如 何把目前的一些技術性工作與長寀的基枟研究工

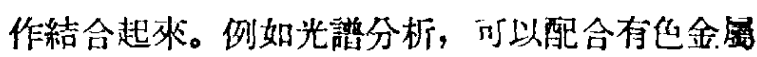

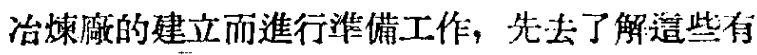

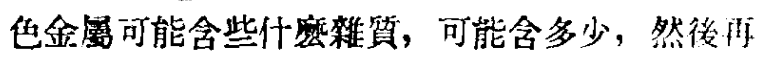
淮行研究。總之, 要使我們的工作不梳陮保際, 就應該經常地瞭解國家經湾建設的規模和永展情 
况, 進行系梳的調查研究, 决定題目的㭙候必須 同時考虑到國家建設的需要與本門科學的殒展。

會議認篇，首先我們必須抓緊特間，根㨜“整 頓綮固, 重點發展, 提高質量, 穞步前進”的方 針，在二三年內把我們的除伍琹固提高起來。在 過去的緖年裹，各單位人員在數量上得到較大的 發展, 這是必要的。現在就必須在原有基礎上， 經過整顿龩固的階段, 總結逼烧年來發展的經驗 訓，篇今後的發展打下基礎。

我們的發展必須是有重點的, 過去應用物理 研究所㩲子撽得太大，理論提高注意不够，天文 台訂的計劃也是無所不包, 這種辦法會分散我們 的力量。缺乏重點, 是不利於工作的開展的。今 後我們礁該學替蘇聯全面發展, 重點使用力量的 辦法, 把我們有限的力量集中在有發展前途而收 效最大的問題上去。

篇了提高我們研究工作的䆩量, 我們不能停 留在現在的階段, 滿意於已有的一些成精, 必須 系統地認㣀地依照正規的工作方法解决科學問 題。科學研究工作, 特别是基礎科學的研究工作、 酞有在長期的䩗苦的勞動中，在脚踏筫地的系統 工作中才能够逐桷深入。物理學、數學科學的四 個單位裹, 普掘地存在着急躁情緒, 逜是不健康 的, 我們應該反對保守, 但是急躁也解决不了任 何問題, 我們必須付出大量的勞動, 葐步前進, 才能得到成績。

在工作中，我們也不應强調要多少儀器才能 工作。固然現代的許多工作要有很多精密的設備 才能進行，但科學上有一傳統，即所謂大科學家 是能压簡單的設備，做出最重要的結果的。颜聯 仍保留造一一優良傳統，他們一方面對於隹該有的 設備, 毫不躊躇地添置, 另一方泊對於簡阿的設

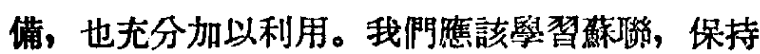
科祭工作中道一優良的傳統。

(3) 培養幹部問題: 上面說過，我們的力量 薑相當薄弱，踓然各研究所集中的力量在國內承 說已算不小, 但與國家的需要比起來還差得很遠。 今後要求再從外面調入高級研究人員, 可能極少。 因此，我門，必須把哏光注親到新生力量，自己 來努力培熬部。

我們齐望每個研究所都能成雼本門學科發展 的基地, 培食幹部時㤫該䍃國家的整個利谷着想,
素虑到我們的幹部, 將來有可能派到産業部閏或 高等學校中去工作。

同時，我們也認篇培養幹部的工作是應該和 其他研究單位及大學密切合作的。逭次綜合大學 會議, 明確了棕合大學的首要任䧄是培食科學研 究人材, 也强調敉學工作與科學研究工作要密切 結合, 因此,科學院與綜合大學的密切配合, 在今 天已經具備了較好的條件，我們各單位必須注意 興大學有關部門加强聯系與合作。會議還認爲,

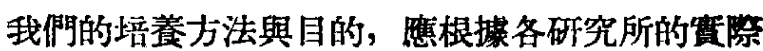
情况，選定某些學科的某一領域作篇重點。

我們要求培飬出來的幹部，必須具有一定高 度的馬克思列蜜主義的思想水平，廣泛的科學知 識，堅實的科學理論基礎和熟練的質驗與運算技 術，同時應該熟悉本門科學的發展歴史及對其他

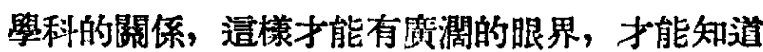
本門科學墢展的方向。對於青年幹部的能讀、能 做、能寫的訓練, 必須抓緊。伴望各研究所訂出 具有具體目標和要求的培食計劃，作篇工作計劃 的一部分。會議上錢偉長敉授介紹的通過有系統 地閱讀文獻和總結過去科學研究成果來培食力學 幹部的方法, 值得各研究所參考。

我們認篇培食青年科學工作幹部，應當依壆 高級研究人員, 同時在訂培養幹部計劃時, 也不 能忽略窝級㸴究人員的提高。

會議决定, 各研究所氏完成設備或具借條件 的工作組, 都應在 1953 年的工作基礎上轉入 高

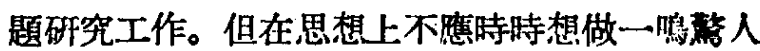
的工作, 篇了解決當前的迫切需要, 或篇今後的 基礎, 在某些方面, 即使工作打是從技術問題深 入或重複一些诵人的經典工作, 也是僧得的。䢐 樣做可使我們的工作開展起來, 尤其初次淮行工 作的青年同志, 在實践中更易於了解研究工作的 意莪。篇了整個物理學工作的提漓, 物理砳究所 的理論組的工作範葦, 應逐步攄大, 担焰起固體 物理學及電子學的理論幹部培養工作。

（4）學習蘇聯問題：在我們向社會主義计會 過渡的過程中，我們不能不衾心感謝偉入的盟邦

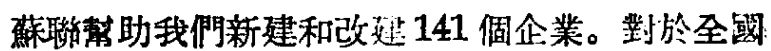
科學工作者來說，這正是一個學習，年聯的好機會。 但是有一點必須明確，學習蘇聯不旅是要學㕷他，

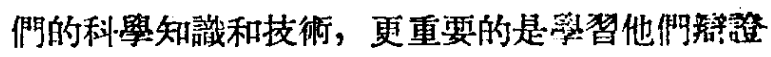


唯物主義的思想方法及批評興自我批評和嚴婣認 真的科學態度，訪蘇代表團的傳澾報告中，清楚 地給我們指出了逭一點。

我們認稨，篇了更有效地學晳蘇聯，必須一

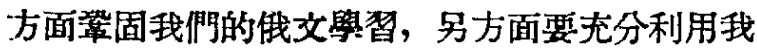
們的書刊, 特別注意總結性的蘇聯交獻, 認真地 學㚙他們每一門科學的先進成果。我們應該組織 力量, 訂好計劃, 系統地翻譯蘇聯文缺, 以供全 國科學研究工作者學晳独聯的寥考，這一點數學 研究所作得較好。在研究工作的參考文躁方面,

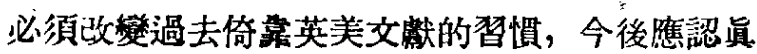

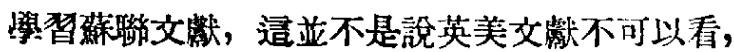
而是在思想上應該端正態度。同時, 我們也應睢可 能地組織若千鹪聯先進科學的報告會和討論會, 以交流我們學楿蘇聯科學的心得與經驗，逐步展 開學術思想上的批評，瓷我們的工作開開新的局 面。

\section{$\equiv$}

根據上迌的討論和看法，這次會議嶉四個單 位的幾年內的具體工作方向和重點都提出了較明 確的意見。這些意見如下:

\section{數需䃑究所}

1. 在基礎理論方面, 以發展數學分析篇重點, 请先是微分方程與函數論; 其他方面已有基礎的, 也不偏廢，適當予以發展。

2.發展力學研究，與北京大學、清華大學合 作, 建立力學研究室, 從培餈幹部着手, 進行有 望際意義的關於彈性、範性、流體力學及宾氣動 力學的研究，亚篇在一定時期後獨立建所準備條 件。

3.結合電子計算機工作，培養計算數學的幹 部。

\section{紫金山天文台}

1.近幾年內不作大發展，主要是培食幹部， 打好基礎; 在培養幹部方面, 與南京大學密切合 作。

2.提高現有研究人員的業務水平，使能具有 較高的理論基礎與学握観測技術，提高觀測工作 的質量及授時工作與編歷計算的集確性。

3.培荟有良好數學與物理學基礎及良好観測
能力的幹部, 以便逐步開展天體物理學、天體演 化學等方面的工作。

應用物理研究所一以發展固體物理研究第 主要方向:

1. 發展結晶學研究, 應用 $\mathrm{X}$ 射線及其他物理 方法, 研究晶體的結構及變化。

2. 建立牛導體研究工作基礎, 首先注意培䓹 人材，總結文獻，特別是蘇聯文獻，严清本門科 學發展的現狀。

3.展開物質磁性的研究。

4. 適當地淮行光譄學、低温物理學方面的工 作。

\section{物理研究所}

1.電子學粗現在進行分米波的呼究，逐步進 入厘米波的研究。

2. 理論組隹逐步擴大範園, 担負起固體物理 學及電子學的理論工作。

3. 其他各組仍按原定为向進行工作，但必須 考虑望際的條件, 重新擬㳬計劃, 使工作建立在 更可靠的基礎上。

以上是我們初步確定的各研究所的方向和重 點, 因篇是初步的, 它將在我們的賽践過程中不 斷加以修改。

會議還討論了在研究工作中具徽增產節約的

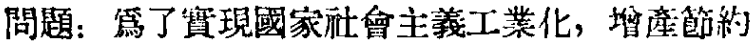
成篇全國人民的重要政治任務，我們科學工作者

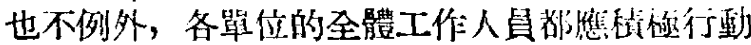
起來, 㩇量把研究工作作好, 保證工作貿量, 第 約所有可能笁約的人力和物力，不健有點滴的浪 費。特别重要的是號召每個人在日常工作中建立. 自覺的節的替慣。

這次會議, 只是討論工作方針, 明確各研究 所的工作方向和重點, 大芜回去之後，還要根據 此次會議的精神，製訂詳細的工作計劃。我們的

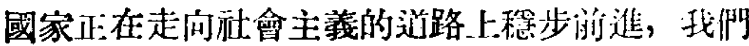
的科學事業有着無限美好的湔途。今天我們的基 礎還很薄弱，在我們面龐還有着很多困難等街我 們去克服。我們必須在科學工作上食成一種健康 楼素的、努力问前的作風，養成深入鋇研不達到 目的决不停止的作風。祇有這樣，我們才能不斷 地在工作中取得勝利。 